\title{
Pengembangan Instrumen untuk Mengukur Kemampuan Berpikir Tingkat Tinggi dalam Mata Pelajaran Matematika di SMA Kabupaten Majene
}

\author{
${ }^{1}$ Hikmah, ${ }^{2}$ Nursyafitri Amin \\ Universitas Sulawesi Barat, Indonesia \\ e-mail: hikmah@unsulbar.ac.id, ${ }^{2}$ nursyafitriamin@unsulbar.ac.id
}

\begin{abstract}
Abstrak
Tujuan umum penelitian ini untuk mengadakan perbaikan pembelajaran berkaitan dengan model tes dan sistem penskorannya. Tujuan khusus penelitian untuk menghasilkan instrumen penilaian kemampuan berpikir tingkat tinggi (Higher Order Thinking) HOT Matematika pada kelas XI SMA yang memenuhi syarat, meliputi: 1) fit dengan PCM dan 1) tingkat kesulitan item Responden siswa SMA kelas XI di Kabupaten Majene terdiri 3 SMA Negeri di Kabupaten Majene yaitu SMA Negeri 1, SMA Negeri 2, dan SMA Negeri 3. Langkah-langkah penelitian meliputi; 1) perancangan instrumen, 2) uji coba instrumen, dan 3) perakitan tes. Tahap perancangan instrumen meliputi: a) Penentuan Tujuan Tes, b) Penentuan Kompetensi yang akan diujikan, c) Penentuan Materi yang Diujikan, d) Penyusunan Kisi-kisi Tes, e) Penulisan Item Berdasarkan Prinsip-prinsip Pengembangan Tes HOT, f) Validasi Item Tes, g) Perbaikan Item dan Perakitan Tes, dan h) Penyusunan Pedoman Penskoran. Tahap uji coba instrumen terdiri: a) Penetapan Subjek Uji Coba (SMA), b) Pelaksanaan Uji coba Tes, dan c) Analisis Data Hasil Uji Coba dengan teknik: (1) Kecocokan Item Instrumen (goodness fit), (2) Reliabilitas, (3) Kurva Karakteristik Item, (4) Indeks Kesukaran, dan (5) Fungsi Informasi dan SEM. Tahap Perakitan Tes untuk Pengukuran.
\end{abstract}

Kata kunci : pengembangan instrumen, penilaian, kemampuan berpikir tingkat tinggi.

\section{PENDAHULUAN}

Mengembangkan kemampuan berpikir harus terus dilakukan karena dapat membentuk individu yang berhasil dalam menghadapi segala tantangan. Hal ini sesuai dengan pendapat Saptaningtyas et al yang menyatakan bahwa kemampuan seseorang untuk dapat berhasil dalam kehidupannya antara lain ditentukan oleh kemampuan berpikirnya, terutama dalam upaya memecahkan masalah yang dihadapinya. Salah satu kemampuan berpikir yang harus dimiliki siswa adalah kemampuan berpikir tingkat tinggi (higher order thinking). Menurut Rofiah et al, kemampuan berpikir tingkat tinggi merupakan kemampuan menghubungkan, memanipulasi, dan mentransformasi pengetahuan serta pengalaman yang sudah dimiliki untuk berpikir secara kritis dan kreatif dalam upaya menentukan keputusan dan memecahkan masalah pada situasi baru

Salah satu tujuan Mata Pelajaran Matematika di SMA adalah agar peserta didik memiliki kemampuan memecahkan masalah yang meliputi kemampuan memahami masalah, merancang model matematika, menyelesaikan model, dan menafsirkan solusi yang diperoleh. Dengan demikian, melalui pembelajaran Matematika diharapkan peserta didik dapat mengembangkan diri dalam berpikir. Peserta didik dituntut tidak hanya memiliki kemampuan berpikir tingkat rendah (lower order thinking), tetapi sampai pada kemampuan berpikir tingkat tinggi

Received December $31^{\text {st }}, 2018$; Revised January $5^{\text {th }}$, 2019; Accepted January $10^{\text {th }}, 2019$ 
(higher order thinking, HOT). Dengan kemampuan berpikir tingkat tinggi ini diharapkan dapat meningkatkan prestasi belajar matematika siswa.

Kemampuan berpikir tingkat tinggi sangat penting dikuasai oleh siswa, karena dengan kemampuan tersebut dapat memotivasi siswa senantiasa memandang setiap masalah dengan kritis, serta mencoba menyelesaikannya secara kreatif. Namun, proses pembelajaran matematika yang berlangsung selama ini hanya menghafal konsep saja tanpa memahami apa yang dipelajari. Akibatnya, hanya sedikit siswa yang mampu mengembangkan kemampuan berpikirnya hingga berpikir tingkat tinggi. Kurang tersedianya soal-soal tes yang didesain khusus untuk melatih siswa agar menggunakan kemampuan bernalarnya dalam menjawab setiap permasalahan yang dihadapi merupakan salah satu penyebab rendahnya siswa dengan kemampuan berpikir tingkat tinggi. Hal ini sesuai dengan pendapat Budiman dan Jailani yang menyatakan bahwa salah satu faktor penyebab rendahnya kemampuan berpikir tingkat tinggi siswa adalah kurang terlatihnya siswa dalam menyelesaikan soal-soal kontekstual, menuntut penalaran, argumentasi dan kreativitas dalam meyelesaikannya.

Permasalahan tersebut harus segera diatasi agar tujuan pembelajaran dapat tercapai secara optimal. Salah satu caranya adalah melalui pembuatan soal-soal penalaran yang didesain khusus untuk melatih siswa dalam mengembangkan kemampuan berpikirnya. Untuk mengukur kemampuan berpikir tingkat tinggi Matematika digunakan tes berbentuk pilihan ganda yang dinamakan Tes Matematika berpikir tingkat tinggi (Mathematic Test for Higher Order Thinking, Math THOT). Untuk itu perlu disusun instrumen penilaian kemampuan berpikir tingkat tinggi matematis yang terdiri atas tes dan pedoman penilaian. Agar dihasilkan instrumen yang andal, diterapkan prinsip-prinsip pengembangan instrumen. Dengan demikian diperlukan adanya penelitian pengembangan instrumen penilaian kemampuan berpikir tingkat tinggi matematis yang terdiri atas tes berpikir tingkat tinggi dan pedoman penilaian.

Untuk mengetahui yang dimaksud berpikir tingkat tinggi (higher order thinking) dapat dilihat definisi menurut Brookhart ( 2010:5) sebagai berikut: Higher Order Thinking Skills atau kemampuan berpikir tingkat tinggi pada dasarnya berarti pemikiran yang terjadi pada tingkat tinggi dalam suatu proses kognitif. Menurut taksonomi Bloom yang telah dirievisi keterampilan berpikir pada ranah kognitif terbagi menjadi enam tingkatan, yaitu pengetahuan, pemahaman, aplikasi, analisis, sintesis, dan evaluasi (Syafa"ah \& Handayani, 2015). Schraw et al. (2011: 191) mengklasifikasikan keterampilan berpikir yang dimiliki Bloom menjadi dua tingkatan yaitu keterampilan berpikir tingkat rendah (Lower Order Thinking Skills) yang terdiri atas pengetahuan dan pemahaman, serta keterampilan berpikir tingkat tinggi (Higher Order Thinking Skills) yang terdiri atas aplikasi, analisis, sintesis, dan evaluasi.

Definisi tersebut menyiratkan beberapa hal, sebagai berikut: (1) Berpikir tingkat tinggi merupakan kemampuan pada ujung atas taksonomi kognitif Bloom, (2) Tujuan pengajaran berdasarkan taksonomi kognitif Bloom melengkapi siswa untuk dapat menerapkan pengetahuan dan keterampilan untuk konteks baru. Maksud baru adalah aplikasi konsep bagi siswa belum terpikirkan sebelumnya, ini berarti belum tentu semua siswa dapat mengetahui sesuatu yang baru yang bersifat universal. (3) Berpikir tingkat tinggi berarti kemampuan siswa untuk menghubungkan pembelajaran mereka terhadap hal-hal lain selain yang pernah diajarkan.

Kemampuan berpikir tingkat tinggi Matematika atau MathHOT adalah kemampuan menganalisis (analyze), mengevaluasi (evalute), dan menciptakan (create) pada bidang Matematika. Kemampuan ini ditunjukkan dalam menyelesaikan persoalan Matematika dengan menganalisis, mengevaluasi, dan menciptakan. Kemampaun ini sebenarnya sudah dibiasakan dalam Matematika, karena Matematika sudah melatih mengembangkan kemampuan berpikir logis, kritis, objektif, memutuskan sesuatu berdasarkan data yang tetap dengan menggunakan metode ilmiah, dan kemampuan untuk komunikasi ilmiah.

Berdasarkan uraian di atas, prinsip penyusunan Tes Kemampuan MhatHOT antara lain. Pengembangan tes menurut Oriondo dan Antonio (1998: 34) terdiri lima tahapan, yakni:

SAINTIFIK Vol. 5, No. 1, Januari 2019: 1-7 
(1) perencanaan tes (planning test), (2) uji coba tes (trying out the test), (3) menetapkan validitas tes (establishing test validity), (4) menetapkan reliabilitas tes (establishing test reliability), dan (5) menafsirkan nilai tes (interpreting the test scores). Berdasarkan model ini, maka pengembangan tes dimulai dari persiapan yang meliputi: penentuan tujuan tes, spesifikasi tes, pemilihan format butir, membuat butir soal, dan mengedit butir soal. Setelah butir-butir soal siap, maka dilakukan uji coba untuk mendapatkan karakteristik tes yang meliputi. Setelah dianalisis hasil uji coba, maka dapat diperoleh validitas dan reabilitas tes. Akhirnya bila telah melakukan pengukuran, maka dapat dilakukan penafsiran skor tes.

\section{METODE PENELITIAN}

Jenis penelitian yang digunakan adalah jenis penelitian pengembangan dengan pendekatan kuantitatif. Penelitian pengembangan instrument ini menggunakan model modifikasi Model Wilson dan Model Oriondo dan Antonio.

Pengembangan awal tes yang berupa penyiapan tes, validasi dan perakitan tes. Langkah-langkah pengembangan instrumen berupa tes menggunakan modifikasi Model Wilson dan Model Oriondo dan Antonio, yakni: (1) perancangan tes, (2) uji coba tes, dan (3) perakitan tes. Tahap perancangan tes meliputi: (1) penentuan tujuan tes, (2) penentuan kompetensi yang diujikan, (3) penentuan materi yang diujikan, (4) penyusunan kisi-kisi tes, (5) penulisan itemberdasarkan prinsip- prinsip pengembangan TesHOT, (6) validasi item tes, (7) perbaikan item dan perakitan tes, dan (8) penyusunan pedoman penskoran. Adapun tahap uji coba tes meliputi: (1) penetapan subjek uji coba (SMA), (2) pelaksanaan uji coba, dan (3) analisis data hasil uji coba. Tahap terakhir dalam pengembangan tes ini adalah perakitan tes.

\section{HASIL DAN PEMBAHASAN}

Ujicoba terbatas instrumen dilakukan di SMA Negeri 1 Majene, SMA 2 Majene,dan SMA 3 Majene. Instrumen yang digunakan berupa tes kemampuan berpikir tingkat tinggi Matematika (MathTHOT) pada Kelas XI SMA yang terdiri dari satu set tes yang masingmasing berisi 20 item dengan 4 item sebagai anchor item. Setiap item tes ini terdiri atas soal dengan 5 pilihan jawaban. Ujicoba terbatas ini dilakukan dengan tujuan untuk mengetahui keterbacaan item-item tes.

Jumlah responden dalam pelaksanaan ujicoba atau testi sebanyak 139 siswa yang berasal dari 3 SMA Neg. di Majene. Adapun rincian jumlah responden masing-masing SMA dinyatakan pada tabel berikut.

Tabel 1 Jumlah Responden dalam Kegiatan Ujicoba

\begin{tabular}{|c|l|c|}
\hline No & \multicolumn{1}{|c|}{ Nama Sekolah } & Jumlah Siswa \\
\hline 1 & SMA Neg. 1 Majene & 45 \\
\hline 2 & SMA Neg. 2 Majene & 59 \\
\hline 3 & SMA Neg. 3 Majene & 35 \\
\hline & Jumlah & 139 \\
\hline
\end{tabular}

\subsection{Hasil Kegiatan Uji Coba}

3.1.1 Kecocokan Item Instrumen (goodness fit)

Pengujian goodness of fit untuk tes secara keseluruhan maupun tiap item dengan program SPSS, yaitu menggunakan nilai korelasi yang dibandingkan dengan kriteria:

$0,40 \leq$ nilai korelasi $\leq 1,00$ soal baik

$0,30 \leq$ nilai korelasi $\leq 0,39$ soal diterima dan diperbaiki 
$0,20 \leq$ nilai korelasi $\leq 0,29$ soal diperbaiki

$0,00 \leq$ nilai korelasi $\leq 0,19$ soal ditolak

Berikut nilai korelasi setiap item soal dengan menggunakan SPSS.

Tabel 2 Nilai korelasi setiap item soal

\begin{tabular}{|c|c|c|c|}
\hline Nomor Soal & Nilai Korelasi & Nomor Soal & Nilai Korelasi \\
\hline 1 & 0,216 & 11 & 0,422 \\
\hline 2 & 0,226 & 12 & 0,383 \\
\hline 3 & 0,216 & 13 & 0,364 \\
\hline 4 & 0,347 & 14 & 0,309 \\
\hline 5 & 0,214 & 15 & 0,320 \\
\hline 6 & 0,224 & 16 & 0,404 \\
\hline 7 & 0,174 & 17 & 0,381 \\
\hline 8 & 0,248 & 18 & 0,440 \\
\hline 9 & 0,430 & 19 & 0,536 \\
\hline 10 & 0,423 & 20 & 0,244 \\
\hline
\end{tabular}

Dari tabel di atas, nampak bahwa ada 6 soal yang baik, 6 soal yang diterima dan diperbaiki, 7 soal yang diperbaiki, dan 1 soal yang ditolak. Artinya ada beberapa soal yang akan diperbaiki. Berdasarkan hasil tersebut, meskipun semua soal valid, belum tentu soal tersebut fit.

\subsubsection{Reliabilitas}

Analisis selanjutnya adalah menentukan tingkat reliabilitas. Untuk mengetahui tingkat reliabilitas, maka dilakukan uji reliabilitas dengan menggunakan SPSS. Berikut kriteria tingkat reliabilitas dengan membandingkan nilai Cronbach's Alpha.

$0,8000 \leq$ Cronbach's Alpha $\leq 1,000$ sangat tinggi

$0,6000 \leq$ Cronbach's Alpha $\leq 0,799$ tinggi

$0,4000 \leq$ Cronbach's Alpha $\leq 0,599$ cukup

$0,2000 \leq$ Cronbach's Alpha $\leq 0,399$ rendah

Cronbach's Alpha $<2$ sangat rendah

Dari output SPSS diperoleh nilai Cronbach's Alpha 0,550. Dapat disimpulkan bahwa tes ini memiliki tingkat reliabilitas yang tinggi.

\subsubsection{Tingkat Kesukaran}

Berdasarkan hasil analisis dengan program SPSS diperoleh tingkat kesukaran item. Berikut rentang tingkat kesukaran berdasarkan nilai mean.

$0,00 \leq$ Nilai mean $\leq 0,30$

sukar

$0,31 \leq$ Nilai mean $\leq 0,70$

sedang

$0,71 \leq$ Nilai mean $\leq 1,00$

mudah

Adapun nilai mean setiap item soal yang diperoleh dengan menggunakan program SPSS sebagai berikut: 
Tabel 3 Nilai Mean setiap Item Soal

\begin{tabular}{|c|c|c|c|}
\hline Nomor Soal & Nilai Mean & Nomor Soal & Nilai Mean \\
\hline 1 & 0,27 & 11 & 0,30 \\
\hline 2 & 0,32 & 12 & 0,41 \\
\hline 3 & 0,40 & 13 & 0,35 \\
\hline 4 & 0,34 & 14 & 0,27 \\
\hline 5 & 0,26 & 15 & 0,35 \\
\hline 6 & 0,31 & 16 & 0,24 \\
\hline 7 & 0,36 & 17 & 0,26 \\
\hline 8 & 0,26 & 18 & 0,24 \\
\hline 9 & 0,20 & 19 & 0,29 \\
\hline 10 & 0,24 & 20 & 0,34 \\
\hline
\end{tabular}

Berdasarkan rentang tingkat kesukaran dan nilai mean setiap item di atas, maka diperoleh tingkat kesukaran setiap item sebagai berikut:

Tabel 4 Tingkat Kesukaran setiap Item Soal

\begin{tabular}{|c|c|c|c|}
\hline Nomor Soal & Nilai Mean & Nomor Soal & Nilai Mean \\
\hline 1 & Sukar & 11 & Sukar \\
\hline 2 & Sedang & 12 & Sedang \\
\hline 3 & Sedang & 13 & Sedang \\
\hline 4 & Sedang & 14 & Sukar \\
\hline 5 & Sukar & 15 & Sedang \\
\hline 6 & Sedang & 16 & Sukar \\
\hline 7 & Sedang & 17 & Sukar \\
\hline 8 & Sukar & 18 & Sukar \\
\hline 9 & Sukar & 19 & Sukar \\
\hline 10 & Sukar & 20 & Sedang \\
\hline
\end{tabular}

Telah disajikan distribusi tingkat kesulitan item secara keseluruhan. Berikut dapat jelaskan tingkat kesulitan item pada masing-masing aspek dan subaspek instrumen. Untuk lebih jelasnya, dapat dilihat pada tabel berikut.

Tabel 5 Tingkat Kesukaran Butir Masing-masing Subaspek

\begin{tabular}{|c|c|c|c|c|}
\hline \multirow[b]{2}{*}{ Aspek } & \multirow[b]{2}{*}{$\begin{array}{l}\text { Sub } \\
\text { Aspek }\end{array}$} & \multicolumn{3}{|c|}{$\begin{array}{c}\text { Materi Matematika SMA } \\
\text { Kelas XI }\end{array}$} \\
\hline & & $\begin{array}{c}\text { Turunan } \\
\text { suatu } \\
\text { Fungsi }\end{array}$ & $\begin{array}{c}\text { Apli } \\
\text { kasi } \\
\text { Turu } \\
\text { nan }\end{array}$ & $\begin{array}{c}\text { Sketsa } \\
\text { Kurva } \\
\text { suatu } \\
\text { Fungsi } \\
\text { dengan }\end{array}$ \\
\hline
\end{tabular}




\begin{tabular}{|c|c|c|c|c|}
\hline & & & & $\begin{array}{l}\text { konsep } \\
\text { turunan }\end{array}$ \\
\hline $\begin{array}{l}\text { Meng } \\
\text { analis } \\
\text { is }\end{array}$ & $\begin{array}{l}\text { Mende } \\
\text { finisik } \\
\mathrm{n}\end{array}$ & $\begin{array}{l}\text { Sukar, } \\
\text { Sedang }\end{array}$ & Sukar & \\
\hline \multirow[t]{2}{*}{$\begin{array}{l}\text { Mengev } \\
\text { aluasi }\end{array}$} & $\begin{array}{l}\text { Menen } \\
\text { tukan }\end{array}$ & $\begin{array}{l}\text { Sedang, } \\
\text { Sedang, } \\
\text { Sukar }\end{array}$ & Sukar & Sukar \\
\hline & $\begin{array}{l}\text { Meme } \\
\text { cahkan }\end{array}$ & $\begin{array}{c}\text { Sedang, } \\
\text { Sedang, } \\
\text { Sukar }\end{array}$ & $\begin{array}{c}\text { Sedan } \\
\text { g, } \\
\text { Sedan } \\
\text { g }\end{array}$ & \\
\hline \multirow[t]{2}{*}{$\begin{array}{l}\text { Mencip } \\
\text { takan }\end{array}$} & $\begin{array}{l}\text { Mene } \\
\text { mukan }\end{array}$ & & & $\begin{array}{l}\text { Sukar, } \\
\text { Sukar, } \\
\text { Sukar, } \\
\text { Sukar }\end{array}$ \\
\hline & $\begin{array}{l}\text { Mengg } \\
\text { unaka } \\
\mathrm{n}\end{array}$ & & $\begin{array}{c}\text { Sedan } \\
\text { g,Suka } \\
\text { r }\end{array}$ & Sedang \\
\hline
\end{tabular}

Berdasarkan tingkat kesulitan item, dapat disajikan 10 item termudah dan 10 item tersulit. Sepuluh item termudah dan sepuluh item tersulit masing-masing disajikan pada tabel berikut.

Tabel 6 Sepuluh Item Termudah dan Tersulit pada Kegiatan Uji Coba

\begin{tabular}{|c|c|c|}
\hline No & 10 Item Termudah & 10 Item Tersulit \\
\hline 1 & 13 & 9 \\
\hline 2 & 3 & 10 \\
\hline 3 & 7 & 16 \\
\hline 4 & 13 & 18 \\
\hline 5 & 15 & 8 \\
\hline 6 & 4 & 5 \\
\hline 7 & 20 & 17 \\
\hline 8 & 2 & 14 \\
\hline 9 & 6 & 1 \\
\hline 10 & 11 & 19 \\
\hline
\end{tabular}

\section{KESIMPULAN}

Kesimpulan harus mengindikasi secara jelas hasil-hasil yang diperoleh, kelebihan dan kekurangannya, serta kemungkinan pengembangan selanjutnya.

Kesimpulan dapat berupa paragraf, namun sebaiknya berbentuk point-point dengan menggunakan numbering atau bullet.

\section{DAFTAR PUSTAKA}

Bloom, B.S., et al. 1979. Taxonomy of Educational Objectives: Handbook I Cognitive Domain. London: Longmans Group Ltd.

Bond, TG and Fox, CM. 2007. Applying the Rasch Model. Fundamental Measurement in the 
Human Sciences ( 2 rd edition). Mahwah, NJ: Lawrence Erlbaum. Bonk.

Brookhart, S. M. 2010. How to Assess Higher Order Thinking Skills in Your Classroom. Alexandria: ASCD.

BSNP. (2006). Standar Kompetensi dan Kompetensi Dasar Mata Pelajaran Matematika Untuk SMA dan MA. Jakarta: BSNP-Depdiknas.

Djemari Mardapi. 2004. Penyusunan Tes Hasil Belajar. Yogyakarta: PPs Universitas Negeri Yogyakarta.

Haladyna, T. M. 1997. Writing Test Item to Evaluate Higher Order Thinking. Boston: Allyn and Bacon.

Haladyna, T. M. 2004. Devoping and Validating Multiple Choise Test Items. New Jersey: Lawrence Erlbaum Associates, Inc.

Madhuri, G. V. Kantamreddi, V. S.S.N and Goteti, P. L. N.S. 2011. Promoting higher order thinking skills using inquiry-based learning. European Journal of Engineering Education.

Nana Sudjana. 1990. Penilaian Hasil Belajar Mengajar. Bandung: PT Remaja Rosdakarya

Nana Sudjana \& Ahmad Rivai. 2003. Teknologi pengajaran. Bandung : Sinar Baru Algensindo 